\title{
PENINGKATAN KEMAMPUAN MENGENAL ANGKA DENGAN MENGGUNAKAN MEDIA PAPAN FLANEL
}

\author{
M. Anggrayni ${ }^{1}$, Ayu Mustika Sari ${ }^{2}$ \\ Fakultas Keguruan dan Ilmu Pendidikan, Universitas Dharmas Indonesia \\ Email: melisaangggrayni81@gmail.com ${ }^{1}$, ayumustikasari10@gmail.com²
}

\begin{abstract}
Abstrak
Penelitian tindakan kelas ini dilatarbelakangi oleh rendahnya hasil belajar anak pada aspek kognitif. Dalam proses pembelajaran guru kurang mengembangkan kemampuan mengenal angka, hal ini telihat dari pembelajaran yang masih bersifat konvensional dengan hanya memanfaatkan papan tulis yang ada di sekolah. Proses pembelajaran terlihat masih bersifat teacher center. Penelitian tindakan kelas ini dilakukan dalam dua siklus, subjek dari penelitian ini adalah anak dari TK Islam Bakti 50 Sungai Rumbai yang berjumlah 10 orang. Instrumen penelitian yang digunakan dalam penelitian ini adalah lembar observasi untuk anak. Persentase hasil penelitian belajar kognitif anak $70 \%$ sudah berada pada tahap Berkembang Sesuai Harapan (BSH), berarti bahwa nilai yang diperoleh anak telah mencapai terget perkembangan kognitif. Berdasarkan penelitian dapat disimpulkan bahwa dengan menggunakan media papan flanel dapat meningkatkan hasil belajar kognitif anak.
\end{abstract}

Kata Kunci: Kognitif, Papan Flanel, Lambang Bilangan.

\begin{abstract}
This classroom action research is based on students' low learning outcomes on cognitive aspects. In learning process, teacher does not much pay attention to develop students' ability to recognize numbers, it can be seen from conventional learning applied by only utilizing a whiteboard provided in the class. The learning process seen is still a teacher center. This research was done in two cycles, the subjects of this research were students of TK Islamic Bakti 50 Kindergarten in Sungai Rumbai that consisted of 10 students. The research instrument used in this research was an observation sheet for students. Result of $70 \%$ of this research indicates that students' learning outcomes have already been classified to "Berkembang Sesuai Harapan" (BSH), it can be seen that the value obtained by the students has reached target of cognitive development aspects. Based on result of this research, it can be assumed that by using the media of flannel boards can improve students' cognitive learning outcomes.
\end{abstract}

Keywords: Cognitive, Flannel Board, Symbol of Numbers.

(C) 2019 M. Anggrayni ${ }^{1}$, Ayu Mustika Sari ${ }^{2}$ Under the license CC BY-SA 4.0

http://jurnal.upmk.ac.id/index.php/pelitapaud 


\section{PENDAHULUAN}

Pendidikan anak usia dini adalah salah satu bentuk penyelenggaraan yang menitik beratkan pada peletakan dasar kearah pertumbuhan fisik, kecerdasan, sosial, emosional, bahasa dan kognitif.. Salah satu aspek dalam pengembangan kognitif adalah mengenal angka. Mengenal angka merupakan bagian tidak terpisahkan dari kehidupan yang sangat diperlukan dalam kehidupan sehari-hari. Kemampuan mengenal angka anak harus dilakukan semenjak anak usia dini. Hanya saja beberapa lembaga pendidikan dalam pembelajarannya kurang menstimulasi anak untuk mengenal angka, seperti menyediakan berbagai macam media/alat, memberikan kesempatan untuk mencoba berbagai cara memainkannya, serta metode dalam meningkatkan kemampuan kemampuan mengenal angka.

Berdasarkan pengamatan awal yang dilaksanakan penulis pada tanggal 19 sampai 24 Agustus 2019 di TK Islam Bakti 50 Sungai Rumbai Kabupaten Dharmasraya semester 1 tahun pelajaran 2019/2020, kegiatan yang dilakukan untuk mengembangkan kemampuan berhitung anak masih bersifat konvensional dengan memanfaatkan papan tulis yang ada di sekolah, serta dalam proses pembelajarannya banyak anak yang ribut dengan temannya yang lain dan guru kurang melibatkan anak dalam proses pembelajaran berhitungnya atau hanya bersumber dari guru saja, sehingga membuat anak menjadi malas, bosan dan jenuh dalam mengikuti kegiatan belajar mengenal angka di TK Islam Bakti 50 Sungai Rumbai Kabupaten Dharmasraya. Ditambah lagi media yang digunakan guru dalam belajar berhitung hanya menggunakan lembar kerja anak atau buku cetak.

Agar anak tidak merasa jenuh, bosan serta malas dalam proses pembelajaran, kewajiban guru harus bisa memfaatkan dan membuat media pembelajaran agar anak merasa senang dan merasa tidak ada beban dalam proses pembelajaran, guru juga harus bisa mengkondisikan suasana kelas agar proses pembelajaran dapat berjalan dengan lancar khususnya pada proses pembelajaran berhitung. Perkembangan kemampuan berhitung pada anak usia dini sangat penting karena dapat diperlukan dalam kehidupan sehari-hari, terutama konsep bilangan yang merupakan dasar bagi pengembangan kemampuan matematika maupun kesiapan untuk mengikuti pendidikan dasar. Menurut Depdiknas (2000:7) Menyatakan bahwa secara umum berhitung permulaan bagi anak usia dini bertujuan untuk mengetahui dasar-dasar pembelajaran berhitung sehingga pada saatnya nanti anak 
akan lebih siap mengikuti pembelajaran berhitung pada jenjang selanjutnya yang lebih kompleks. Sedangkan secara khusus, dapat berpikir logis dan sistematis sejak dini melalui pengamatan terhadap bendabenda konkrit, gambar-gambar atau angkaangka yang terdapat disekitar, anak dapat menyesuaikan dan melibatkan diri dalam kehidupan bermasyarakat yang dalam kesehariannya memerlukan kemampuan berhitung, ketelitian, konsentrasi, abstrak dan daya apresiasi yang lebih tinggi, memiliki pemahaman konsep ruang dan waktu serta dapat memperkirakan kemungkinan urutan sesuai peristiwa yang terjadi di sekitarnya, dan memiliki kreatifitas dan imajinasi dalam menciptakan sesuatu secara spontan'.

Menggunakan media papan flanel diharapkan dapat meningkatkan kemampuan anak dalam belajar mengenal angka di TK Islam Bakti 50 Sungai Rumbai. Papan flanel adalah salah satu media pembelajaran yang mudah digunakan serta ditemukan. Menurut Hujair AH. Sanaky (2011:61) papan flanel termasuk salah satu media pembelajaran visual dua dimensi, yang dibuat dari kain flanel yang ditempelkan pada sebuah papan atau tripleks, kemudian membuat guntingan-guntingan kain flanel atau kertas rempelas yang diletakkan pada bagian belakang gambar-gambar yang berhubungan dengan bahan-bahan pelajaran. Papan flannel adalah papan yang berlapis kain flannel, sehingga gambar yang akan disajikan dapat dipasang dan dilepas dengan mudah dan dapat dipakai berkali-kali. Menurut Daryanto (2012 : 23), kelebihan media papan flanel antara lain: 1) Dapat dibuat sendiri, 2) Item - item dapat diatur sendiri, 3) Dapat dipersiapkan terlebih dahulu, 4) Item-item dapat dipergunakan berkali-kali, 5) Memungkinkan penyesuaian dengan kebutuhan anak, 6) Menghemat waktu dan tenaga.

\section{METODE PENELITIAN}

\section{Jenis Penelitian}

Penelitian ini merupakan penelitian tikan kelas yang mana penelitian ini bertujuan untuk memperbaiki proses pemebelajaran.

\section{Waktu dan Tempat Penelitian}

Penelitian ini dilaksanakan pada TK Islam Bakti 50 Sungai Rumbai Kabupaten Dharmasraya. Tahun pelajaran 2019/2020 Semester I. Waktu peneliti berpedoman pada kalender akademik sekolah semester ganjil 2019.

\section{Subjek Penelitian}

Subjek penelitian ini adalah peserta didik TK Islam Bakti 50 Sungai Rumbai 
Kabupaten Dharmasraya tahun pelajaran 2019/2020 dengan jumlah anak 10 orang, yang terdiri dari 6 orang anak laki-laki dan 4 orang anak perempuan.

\section{Prosedur Penelitian}

Penelitian ini merupakan penelitian tindakan kelas (PTK). Penelitian Tindakan Kelas terdiri dari empat tahapan yaitu perencanaan, pelaksanaan, pengamatan, dan refleksi. Berikut alur dari tahapan penelitin ini:
Bakti 50 Sungai Rumbai yang sekaligus menjadi sumber data dari penelitian ini. Instrumen Dalam penelitian ini instrumen yang digunakan adalah lembar obsrvasi anak.

\section{Perencan}

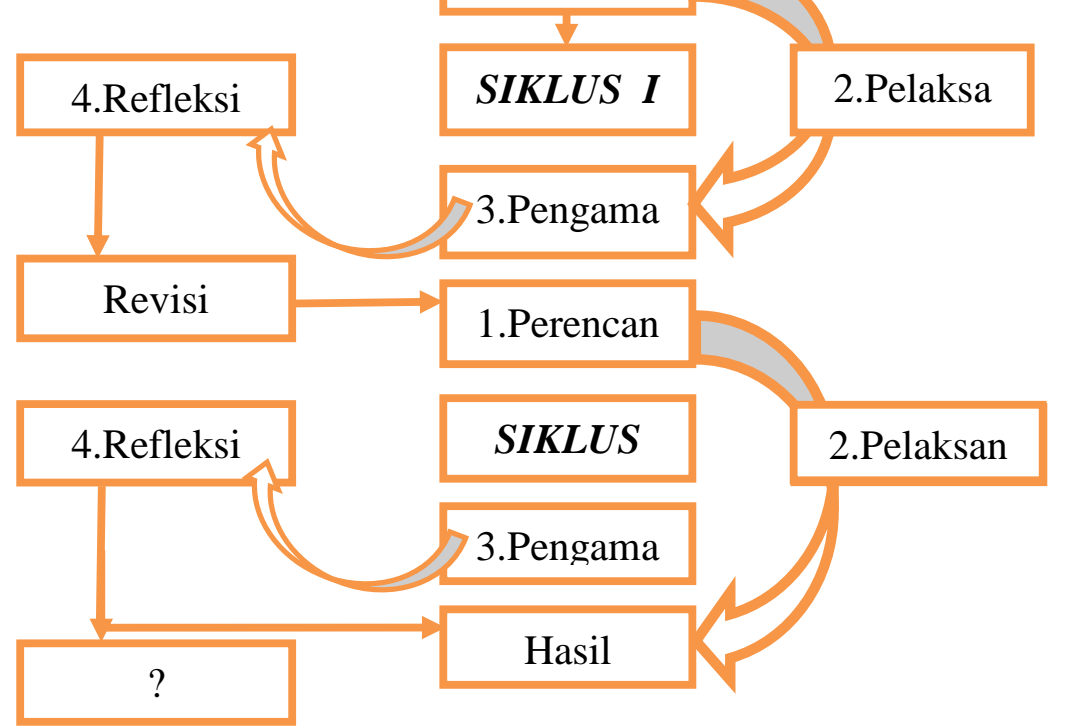

Bagan 1. Alur Penelitian PTK yang dimodifikasi dari Arikunto (2012:16)

\section{Data, Intrumen, dan Teknik}

\section{Pengumpulan Data}

Data

Data dalam penelitian ini adalah data primer yang merupakan data yang peneliti kumpulkan langsung dari murid TK Islam
Teknik penggumpulan Data

Teknik pengumpulan data yang digunakan untuk mengumpulkan data dalam penelitian ini yaitu observasi dan dokumentasi.

\section{Teknik Analisis Data}


Analisis ini dilakukan pada saat refleksi apakah nilai belajar anak sudah mencapai ketuntasan diatas 70\%. Hasil analisis ini digunakan untuk melakukan perencanaan lanjutan dalam siklus

$$
P=\frac{\sum \text { siswa yang tuntas belajar }}{\sum \text { siswa }} \times 100 \%
$$

selanjutnya. Hasil analisis juga dijadikan bahan refleksi dalam memperbaiki rancangan pembelajaran atau bahkan mungkin sebagai bahan pertimbangan dalam penentuan model pembelajaran yang tepat. Arikunto, (2012:264) untuk menghitung persentase ketuntasan belajar digunakan rumus sebagai berikut:

Ket:

$$
\begin{array}{cl}
\mathrm{P} & =\text { Persentase Tingkat Perubahan } \\
100 & =\text { Bilangan Tetap }
\end{array}
$$

\section{HASIL PENELITIAN DAN PEMBAHASAN}

\section{Perencanaan}

Tahap perencanaan yang dilakukan oleh peneliti yaitu sebagai berikut:

Peneliti menyusun Rencana

Pelaksanaan Pembelajaran Harian sesuai dengan tema dan RPPH sekolah. Menyiapkan alat dan bahan yang akan digunakan untuk mendukung kegiatan pembelajaran yang akan dilakukan dalam pelaksanaan kegiatan pembelajaran mengenal angka menggunakan papan flanel. Mempersiapkan lembar pengamatan dan alat dokumentasi kegiatan untuk melihat peningkatan kemampuan mengenal angka pada anak.

\section{Pelaksanaan}

Pelaksanaan pembelajaran mengenal angka dengan menggunakan papan flanel di TK Islam Bakti 50 Sungai Rumbai Kabupaen Dharmasraya siklus 1 dilaksanakan tiga kali pertemuan. Pertemuan pertama dilaksanakan pada tanggal 14 Oktober 2019, pertemuan kedua pada tanggal 15 Oktober 2019, dan pertemuan ketiga pada tanggal 16 Oktober 2019.

Pelaksanaan pembelajaran dibagi dalam tiga tahapan, yaitu:

Pendahuluan, pada kegiatan awal pembelajaran anak-anak berbaris masuk ke ruang kelas dan duduk. Guru memberi salam, mengajak anak untuk berdoa bersama-sama dan menanyakan hari. Kemudian guru bercerita kepada anakanak, bergerak dan mengajak bernyanyi tentang binatang. Guru menjelaskan kegiatan apa saja yang akan dilakukan pada hari itu.

Kegiatan inti terdiri dari tiga kegiatan, yaitu pada ranah matematika (1) memasangkan angka sesuai dengan gambar (2) menunjukkan angka berdasarkan jumlah gambar (3) membilang 
gambar sesuai dengan angka. Ranah bahasa menceritakan kembali tentang gambar, ranah seni mewarnai gambar. Pada penelitian ini pembelajaran meningkatkan kemampuan kognitif pada memasangkan angka sesuai jumlah gambar 1-20, menunjuk angka 1-20, membilang gambar sesuai angka 1-20. Terlebih dahulu anak dibagi atas tiga kelompok. Anak diminta duduk di kursi. Gambar dan angka diletakkan di atas meja. Papan flanel di letatakkan di depan kelas, sehingga anak dapat memilih,mencari angka, gambar dan dapat menempelkanya ke papan flanel yang ada di depan kelas. Kegiatan dimulai dengan guru memperlihatkan media yang akan digunakan yaitu papan flanel, kartu angka dan gambar kemudian guru menjelaskan cara menggunakannya. Media tersebut digunakan ketika guru menjelaskan ranah matematika. Caranya guru bertanya kepada anak media apa yang dibawa, menjelaskan gambar dan angka. Dalam satu hari guru membuka tiga ranah dalam satu ranah dikerjakan dalam dala waktu bersama-sama. Setelah anak selesai pada area matematika barulah anak menuju area berikutnya. Pada kegiatan ini terlihat anak ingin mencoba menghitung gambar, mengenal angka dan menempelkan pada papan flanel, namun ada beberapa anak yang takut dan tidak mau menghitung gambar karena takut salah. Guru memberi motivasi dan bimbingan kepada anak yang masih kesulitan dalam melakukan kegiatan.

Pada kegiatan akhir atau setelah istirahat anak diajak untuk bernyanyi, dilanjutkan tanya jawab dengan mereview bersama anak tentang kegiatan yang telah dilakukan pada hari itu dan memberi tahu kegiatan yang akan dilaksanakan esok hari. Kemudian guru dan anak berdoa bersama, pesan-pesan guru, salam, dan penutup.

\section{Pengamatan}

Berdasarkan hasil kegiatan pembelajaran mengenal angka dengan menggunakan media papan flanel pada siklus 1 pertemuan 1 dapat dilihat pada tabel berikut ini:

Tabel 1. Mengenal Angka Siklus 1 Pertemuan 1

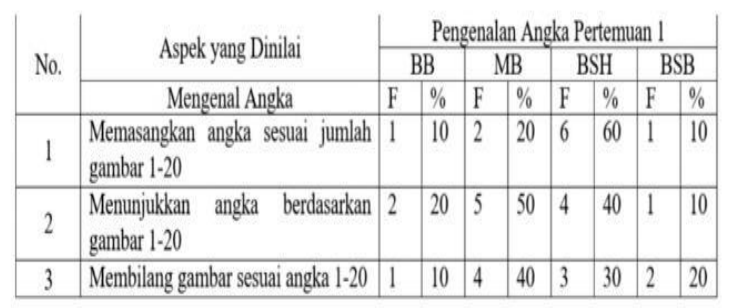

Hasil pengamatan terhadap kemampuan anak mengenal angka dapat dilihat pada tabel di bawah ini.

Tabel 2. Mengenal Angka Siklus 1 Pertemuan 2 


\begin{tabular}{|c|c|c|c|c|c|c|c|c|c|}
\hline \multirow{3}{*}{ No. } & \multirow{2}{*}{ Aspek yang Dinilai } & \multicolumn{8}{|c|}{ Pengenalan Angka Pertemuan 2} \\
\hline & & & BB & & $\mathbb{B}$ & & SH & & $B$ \\
\hline & Mengenal Angka & $\mathrm{F}$ & $\%$ & $F$ & $\%$ & $\mathrm{~F}$ & $\%$ & $F$ & $\%$ \\
\hline 1 & $\begin{array}{l}\text { Memasangkan angka sesuai jumlah } \\
\text { gambar } 1.20\end{array}$ & 0 & 0 & 3 & 30 & 6 & 60 & 1 & 10 \\
\hline 2 & $\begin{array}{l}\text { Menunjukkan angka berdasarkan } \\
\text { gambar 1-20 }\end{array}$ & 1 & 10 & 5 & 50 & 5 & 50 & 1 & 10 \\
\hline 3 & Membilang gambar sesuai angka 1.20 & 0 & 0 & 5 & 50 & 3 & 30 & 2 & 20 \\
\hline
\end{tabular}

Sedangkan untuk hasil pengamatan terhadap kemampuan anak siklus 1 pertemuan ketiga dapat dilihat pada tabel berikut:

\begin{tabular}{|c|c|c|c|c|c|c|c|c|c|}
\hline \multirow{3}{*}{ No. } & \multirow{2}{*}{ Aspek yang Dinilai } & \multicolumn{8}{|c|}{ Pengenalan Angka Pertemuan 3} \\
\hline & & \multicolumn{2}{|c|}{ BB } & \multicolumn{2}{|c|}{ MB } & \multicolumn{2}{|c|}{ BSH } & \multicolumn{2}{|c|}{ BSB } \\
\hline & Mengenal Angka & $F$ & $\%$ & $F$ & $\%$ & $\mathrm{~F}$ & $\%$ & $\mathrm{~F}$ & $\%$ \\
\hline 1 & $\begin{array}{l}\text { Memasangkan angka sesuai } \\
\text { jumlah gambar } 1.20\end{array}$ & 0 & 0 & 2 & 20 & 7 & 70 & 1 & 10 \\
\hline 2 & $\begin{array}{l}\text { Menunjukkan angka berdasarkan } \\
\text { gambar } 1 \cdot 20\end{array}$ & 0 & 0 & 1 & 10 & 7 & 70 & 2 & 20 \\
\hline 3 & $\begin{array}{l}\text { Membilang gambar sesuai angka } \\
1-20\end{array}$ & 0 & 0 & 0 & 0 & 8 & 80 & 2 & 20 \\
\hline
\end{tabular}

\section{Refleksi}

Bedasarkan hasil pengamatan penelitian sudah terlihat keberhasilan pembelajaran yang sudah $80 \%$ berada pada taraf BSH dan BSB, karena sudah pada keberhasilan $80 \%$ maka siklus penelitian dihentikan. Sesuai dengan hasil penelitian (Cahyati, 2018) bahwa media dapat meningkatkan kemampuan perkembangan anak dalam mengenal angka.

\section{SIMPULAN}

Berdasarkan hasil penelitian dan pembahasan yang telah diuraikan pada bab sebelumnya, maka dapat di ambil kesimpulan bahwa berdasarkan penelitian yang telah penulis lakukan bahwa melalui papan flanel dapat meningkatkan kemampuan kognitif anak dalam bidang kemapuan mengenal angka. Kemampuan memasangkan angka sesuai jumlah gambar 1-20, menunjukkan angka berdasarkan gambar 1-20, membilang gambar sesuia angka 1-20 meningkat signifikan dengan $80 \%$ anak berada pada pada taraf Berkembangna Sangat Baik (BSB) dan Berkembang sesuai harapan $\mathrm{BSH}$.

\section{DAFTAR PUSTAKA}

Cahyati, Nika. (2018). Kemampuan Mengenal Angka Melalui Media Memancing bola angka. Jurnal pelita PAUD, Vol.2, No.2, 200-2015.

Daryanto. (2010). Media Pembelajaran. Padang: Sukabina Perss.

Depdiknas. (2003). Undang-Undang No. 20 Tahun 2003. Jakarta

Arikunto, Suharsimi dkk. (2012). Penelitian Tindakan Kelas, Jakarta: PT Bumi Aksara.

Hujair, AH Sanaky. (2011). Media Pembelajaran. Yogyakarta :Kaukaba. 